\title{
Die invloed van verbruikers se persepsie en houdings in die vorming van winkelbeeld
}

\author{
C.J. Jooste \\ Departement Bedryfsekonomie, Universiteit van die Oranje-Vrystaat
}

\begin{abstract}
The influence of consumer's perception and attitudes in formIng retail store images. The consumer's image of a specific retail store is influenced by functional inputs such as the quality and variety of products, price policy, advertising, sales personnel, and external and internal appearance of the store. Several subjective forces are also active in the process of store image creation and are due to the consumer's individual evaluation of the above-mentioned functional forces. The operation of these subjective forces can be better understood if the factors that influence consumer behaviour such as motivation, perception, attitudes, learning experiences, personality, culture, social groups and the family are taken into account. In this article two of these subjective factors, namely perception and attitudes, are analysed to illustrate how the functional inputs are revised into a specific store image.

S. Afr. J. Bus. Mgmt. 1980, 11: $102-107$
\end{abstract}

Die beeld wat verbruikers van 'n kleinhandelsinstelling vorm, word deur bepaalde funksionele insette soos verskeidenheid en gehalte van voorraad, prysbeleid, advertensies, verkoopspersoneel, en eksterne en interne voorkoms van die winkel beinvloed. In die beeldvormingsproses is daar egter ook subjektiewe kragte werksaam wat grootliks te wyte is aan die verbruikers se individuele evaluasie van bogenoemde funksionele aspekte, en dié kan beter begryp word indien gelet word op die faktore wat verbruikersgedrag beïnvloed, byvoorbeeld behoeftes en motiewe, persepsie, houdings, leer-ervaring, persoonlikheid, kultuur, sosiale groepe en die gesin. In hierdie artikel word twee van hierdie subjektiewe faktore, naamlik persepsie en houdings, in meer detail ontleed om te illustreer hoe die funksionele insette verwerk word tot 'n bepaalde winkelbeeld.

S.Afr. Tydskr. Bedryfsl. 1980, 11: $102-107$
Uit ' $n$ bestudering van 'n verskeidenheid omskrywings van die begrip winkelbeeld, blyk dit duidelik dat winkelbeeld ' $n$ komplekse en ingewikkelde begrip is, saamgestel uit die verbruiker se evaluasie van tasbare en ontasbare faktore. Die beeld wat verbruikers van 'n spesifieke winkel vorm, word dus beinvloed deur funksionele aktiwiteite binne die beheer van kleinhandelsbestuur, byvoorbeeld die gehalte en verskeidenheid van voorraad wat te koop aangebied word, die prysbeleid, advertensies, en die voorkoms en uitleg van die winkel. Alhoewel dit waar is dat hierdie funksionele aspekte groot invloed uitoefen op verbruikers se indrukke van 'n winkel, bevat die beeldvormingsproses egter ook 'n subjektiewe element wat hoofsaaklik toe te skryf is aan die verbruiker se individuele evaluasie van die funksionele aspekte - 'n evaluasie wat dus in 'n mate buite die beheer van kleinhandelsbestuur is.'

Die proses waardeur verbruikers die funksionele insette in die beeldvormingsproses op 'n subjektiewe wyse tot 'n winkelbeeld verwerk, kan begryp word deur die ontleding van verbruikersgedrag. Verbruikersgedrag word basies deur twee groepe veranderlikes bepaal: eerstens daardie veranderlikes wat intern tot die individu is, die sogenaamde basiese determinante soos die verbruiker se behoeftes, motiewe, persoonlikheid, persepsie, houdings, oortuigings en leer-ervaring; en tweedens veranderlikes wat ekstern tot die individu is, die sogenaamde omgewingsinvloede soos kultuur, sosiale groepe, gesin, ekonomieseen ondernemingsinvloede. ${ }^{2}$ pp 819

Ten opsigte van voorafgaande is die doel van hierdie artikel om te konsentreer op die beskrywing van twee basiese determinante van verbruikersgedrag in 'n poging om lig te werp op 'n deel van die subjektiewe evaluasieproses waardeur verbruikers die funksionele insette in die beeldvormingsproses verwerk tot 'n winkelbeeld. Die twee determinante van verbruikersgedrag wat ontleed sal word, is persepsie en houdings.

\section{Persepsie as beïnvloeder van verbrulkers se Inter- pretasie van funksionele insette}

Waar 'n verbruiker se behoeftes en motiewe die grondslag lê vir verbruikersgedrag en as voorwaarde vir enige verbruikersoptrede beskou word, word die verbruiker se reaksie en optrede ten opsigte van 'n bepaalde motivering-stimulus in 'n groot mate bepaal deur sy persepsie van die betrokke stimulus. Persepsie kan op die eenvoudigste wyse beskou word as die proses waardeur dit wat 
deur die menslike sintuie waargeneem word, só geïnterpreteer word dat dit vir die menslike verstand moontlik is om dit te kan verstaan en te begryp. ${ }^{2, p p} 137-138$ As 'n verbruiker byvoorbeeld vertel dat 'n sekere afdelingswinkel produkte van 'n hoë kwaliteit te koop aanbied, dan is hy as't ware besig om te vertel van dit wat hy deur sy sintuiglike ondervinding waargeneem het.

Persepsie omvat meer as net bloot dit wat deur middel van die sintuie waargeneem word; die persepsieproses behels ook die interpretasie van hierdie gewaarwordinge in die lig van onder andere vorige ondervindings, die omgewing en toestande in die persoon self. Myers en Reynolds stel dit soos volg: 'perception . . . involves the sum total of sensory impressions from the environment plus the individual's own "fitting in" to complete the picture. The process of perception stands midway along a continuum of sensing to thinking. ${ }^{3, p 3}$ Dit wat die verbruiker dus sien of hoor of voel, proe of ruik, word deur die verbruiker 'verwerk' tot dit wat hy waarneem. Persone sal ook dieselfde stimuli verskillend interpreteer as gevolg van verskille in, onder andere, hul vorige ondervindings, hul agtergrond, hul behoeftes, ensovoorts. Dit verklaar ook waarom verbruikers nie eenders reageer ten opsigte van dieselfde prikkel nie, en dus ook nie eenders reageer ten opsigte van dieselfde winkelbeeldbeïnvloedende faktor nie.

Die persepsies van verbruikers het 'n direkte invloed op bemarking, want hoe beter die kleinhandelaar die verbruiker se persepsie begryp, hoe effektiewer kan hy in die behoeftes van die verbruiker voorsien. Uit 'n bemarkingsoogpunt is dit belangrik om te weet hoe verbruikers winkels, produkte, promosiepogings, ensovoorts, persepsueer. Die kleinhandelaar is veral geïnteresseerd in hoe die verbruiker sy winkel waarneem - met ander woorde watter indruk die verbruiker van die onderneming as geheel vorm. So kan die verbruiker 'n gunstige indruk hê, verskillende afdelings van dieselfde winkel verskillend waarneem, verskillende verbruikers verskillende indrukke van dieselfde winkel vorm, ensovoorts.

\section{Eienskappe van persepsie}

Die invloed van persepsie op verbruikersgedrag kan verduidelik word aan die hand van die volgende eienskappe van persepsie, naamlik die feit dat persepsie subjektief, selektief, tydelik en samevattend is.

- Persepsie is subjektief in dié sin dat dit slegs in die verstand van die mens bestaan. Die verbruiker is as gevolg hiervan in staat om slegs dit waar te neem wat hy of sy graag wil waarneem. As gevolg van hierdie subjektiewe aard van persepsie kan die kleinhandelaar voordeel behaal deur die klem te laat val op dit waarvoor die verbruiker 'n voorliefde of afkeur of vooroordeel het. ' $n$ Verbruiker se persepsie is voorts subjektief in dié sin dat dit wat fisies waargeneem word, geïnterpreteer kan word in die lig van die verbruiker se vorige ondervindings, sy houdings, sy gesindheid en aspirasies. Die beeld wat die verbruiker van 'n bepaalde kleinhandelswinkel vorm, sal dus nie net afhang van sekere funksionele faktore soos voorraad wat aangehou word, prysbeleid en uitleg van die winkel nie, maar ook van die wyse waarop die verbruiker hierdie faktore persepsueer. 'For example, a customer entering a store "perceives" things that he does not "see". He "sees" the physical items, such as the building, fixtures, merchandise, people; his "perception", however is influenced by previous experience in shopping in the store, by conversations with friends, and the like. Thus he may perceive the outlet to be a warm, friendly atmosphere, conducive to shopping and lingering, if his predisposition has been pleasant."

- Persepsie is selektief in dié sin dat 'n verbruiker nie die groot verskeidenheid stimuli waaraan hy blootgestel word, kan waarneem nie - hy is selektief en ignoreer sekere van die stimuli. Die verbruiker tree selektief op omdat hy op ' $n$ bepaalde tydstip menslikerwys net van ' $n$ beperkte aantal prikkels bewus kan wees. Die verbruiker kan nie op al die prikkels reageer nie - hy soek daardie prikkels uit wat die aankoopshandeling vir hom hanteerbaar maak. Die verbruiker is voorts meer geneig om die prikkels uit te soek wat ooreenstem met sy waardesisteem en dié wat vir hom 'n bedreiging inhou te elimineer. So byvoorbeeld sal tevrede verbruikers minder geneig wees om inligting te soek wat betref mededingende produkte en winkels; en indien sulke inligting wel ontvang word, sal dit baie waarskynlik geïgnoreer word. Verbruikers leer gevolglik om hul aandag toe te spits op sekere aspekte en om ander te ignoreer. Die kleinhandelaar moet gevolglik daarna streef om die verbruiker se aandag op ' $n$ besondere wyse te trek. So moet daar byvoorbeeld iets besonders in ' $n$ advertensie wees wat deur bogenoemde verskansing kan dring, of produkte moet op so 'n wyse in ' $n$ winkel uitgestal word dat dit die verbruiker se persepsieveld binnedring en dus ' $n$ positiewe beeld by die verbruiker laat wat betref die tipe en verskeidenheid produkte wat die betrokke kleinhandelaar te koop aanbied.

- Die tydelike aard van persepsie is 'n verdere eienskap wat verbruikersgedrag beinvloed. Persepsie is dikwels van korte duur met die gevolg dat kleinhandelaars deur middel van hul produkte en advertensies verbruikers se aandag net vir ' $n$ kort tydperk behou. Die beeld wat verbruikers van ' $n$ winkel vorm is dus veranderbaar en nie permanent nie. Gevolglik kan 'n kleinhandelaar ' $n$ aspek wat sy beeld skaad, regstel en daardeur ' $n$ nuwe beeld by die verbruikers skep.

- Persepsie is 'n samevattende handeling, met ander woorde verbruikers neig daartoe om verskillende gewaarwordinge saam te vat in een gesamentlike geheel. Hierdie eienskap van persepsie verklaar waarom verbruikers geneig is om al die kenmerke van 'n winkel saam te vat in die beeld wat die verbruiker van sy spesifieke winkel vorm. In sy definisie van die begrip 'beeld' beklemtoon Enis juis hierdie aspek: 'An image is an abstraction, a simplification of reality by the individual so that he can think about the totality of the entity in question'.s

\section{Faktore wat die vorming van persepsie beinnvloed}

Die faktore wat die persepsieproses beïnvloed, verteenwoordig beide fisiese en subjektiewe faktore en kan aan die hand van Walters in die volgende groepe ingedeel word: tegniese faktore, verstandelike gereedheid, vorige 
ondervindings, stemming, en sosio-kulturele faktore. $^{2,}$ pp. $150-157$

- Tegniese faktore as beinvloeder van persepsie verwys na die werklike objek waarvan die verbruiker 'n persepsie vorm. Die objek kan oor sekere tegniese kenmerke beskik wat die persepsieproses beïnvloed. So byvoorbeeld trek groter voorwerpe makliker aandag as kleiner voorwerpe en word grootte en gehalte dikwels met mekaar in verband gebring in dié sin dat groter winkels outomaties beter geag word as kleiner winkels. Die aanwending van kleure, beweging en kontraste is verdere tegniese faktore wat die persepsieproses kan beïnvloed. Dit verklaar ook waarom die uiterlike en innerlike voorkoms van 'n winkel 'n bepaalde beeld tot die verbruiker kan projekteer. Die kleinhandelaar moet daarmee rekening hou dat elke vierkante meter in die winkel dus aangewend moet word om die winkel aan die verbruikers 'te verkoop' en gevolglik is die fisiese uitleg van die winkel, die toerusting wat vir uitstallings gebruik word, die beligting, die gebruik van kleurskemas, trouens enigiets wat die verbruiker kan sien, hoor, voel, ruik en proe, belangrik vir die skepping van 'n bepaalde atmosfeer en beeld. ${ }^{4 .} \cap 153$. Die gebruik van kleure is waarskynlik dié faset in die interne ontwerp van 'n winkel wat die grootste visuele trefkrag het en wat, indien dit korrek benut word, ' $n$ besondere invloed het op die atmosfeer wat in 'n winkel of gedeelte van 'n winkel geskep word. Indien kleurskemas met oorleg gekies word, kan dit 'n baie heilsame invloed uitoefen op die omgewing waarbinne die verkoopstransaksie plaasvind want daar bestaan geen twyfel dat sekere kleure die trefkrag van sekere produkte vergroot nie, terwyl ander weer die trefkrag belemmer. So byvoorbeeld word rooi as 'n kleur beskou wat aptyt bevorder, terwyl pastelkleure gewild is by ondernemings of afdelings wat kosmetiese ware, babaklere en damesonderklere verkoop. ${ }^{6}$ Oranje weerspieël warmte en lewenskrag, pers is 'n diep, ryk kleur wat dikwels geassosieer word met koningskap, geheimsinnigheid en erns, terwyl groen aangewend word om 'n klein ruimte groter te laat vertoon.'

- Die menslike verstand beïnvloed persepsie op verskillende wyses. Die verbruiker se denke kan byvoorbeeld sy persepsie beinvloed - so sal 'n verbruiker wat dienste verlang baie moeilik die diskontohuis as 'n moontlike aankoopplek oorweeg. 'n Verdere manier waarop die menslike verstand persepsie beïnvloed, is die feit dat daar seleksie van stimuli plaasvind omdat die spanwydte van aandag beperk is. Gevolglik sal 'n eenvoudiger advertensieboodskap wat op die punt af is dikwels 'n groter effek op die verbruiker hê as een wat te veel inligting bevat.

- 'n Verbruiker se persepsie op 'n bepaalde tydstip word ook beïnvloed deur sy vorige ondervindings. So sal 'n gunstige of ongunstige ondervinding by 'n bepaalde winkel die verbruiker se beeld van die winkel in die toekoms onderskeidelik gunstig of ongunstig beïnvloed.

- Stemming as beïnvloeder van persepsie verwys na 'n persoon se gesindheid, houding en gemoedstoestand. 'n Pessimistiese persoon sal die wêreld rondom heel- temal anders waarneem as 'n optimis. Die kleinhandelaar kan deur die uiterlike voorkoms van die winkel, vensteruitstallings, interne uitleg, musiek wat gespeel word, en tipe voorraad wat aangehou word, bepaalde stemmings reflekteer, hetsy oudmodies, tradisioneel, prestige of modieus.

- 'n Verbruiker se persepsie word ten slotte beïnvloed deur sosiale en kulturele faktore soos byvoorbeeld die rol wat die persoon speel of wens om te speel in die gemeenskap, sy sosiale status en die kulturele ag. tergrond waarteen hy groot geword het. Ter illustrasie die volgende voorbeeld: 'A consumer oriented toward social climbing may perceive certain products as being inferior because he knows that upperclass families do not buy them. Yet a consumer who has made it socially and financially may show contempt for prestige products and brands and practice a kind of inverse snobbery.' ${ }^{2 . p 156}$ Bogenoemde voorbeeld kan ook ten opsigte van kleinhandelswinkels van toepassing gemaak word. 'n Verbruiker kan 'n bepaalde winkel waarneem as die plek waar die persone met 'n hoë aansien koop, terwyl 'n ander winkel weer vermy word omdat die verbruiker hom nie wil assosieer met die klas mens wat volgens sy mening die winkel ondersteun nie.

\section{Houdings se invloed op verbruikers se interpretasie van funksionele insette}

Waar persepsie, soos dit duidelik uit die vorige afdeling geblyk het, die interpretasie van boodskappe en stimuli deur middel van die sintuie behels, kan houdings breedweg beskou word as die gemoedstoestand wat voortspruit uit daardie interpretasie. Hierdie gemoedstoestand of gevoel teenoor ' $n$ bepaalde objek soos 'n handelsmerk of winkel, sal 'n definitiewe invloed uitoefen op die optrede en gedrag van die verbruiker.

Die begrip houding is baie moeilik omskryfbaar, aangesien daar soveel verskillende skole van denke aangaande hierdie begrip bestaan. ${ }^{8}$ Kat $z$ definieer houdings as: '... the predisposition of the individual to evaluate some symbol or object or aspect of his world in a favorable or unfavorable manner', terwyl Stanton die volgende definisie verstrek: 'Attitudes may be defined as a person's enduring favorable or unfavorable cognitive evaluations, emotional feelings or action tendencies toward some object or idea.' ${ }^{10}$ Walters sê: ' . . . attitude is the relatively lasting manner whereby the perceptions and motives of consumers are organized toward certain market objects, events or situations. Thus consumer preference or predispositions to act toward some specific market-oriented goal is that individual's consumer attitude.,2, p 160

Uit hierdie definisies is dit duidelik dat verbruikers se houdings beide gunstige en ongunstige evaluasies bevat. 'n Gunstige evaluasie kan die verbruiker motiveer om 'n spesifieke produk te koop of om sy aankope by 'n spesifieke winkel te doen, terwyl 'n negatiewe evaluasie weer daartoe kan lei dat 'n verbruiker 'n bepaalde produk of winkel sal vermy.

\section{Funksies van houdings}

Houdings vervul basies vier funksies wat verbruikersgedrag kan beïnvloed, naamlik 'n aanpassingsfunksie, 'n 
ego-beskermende funksie, 'n waarde-uitbeeldende funksie en 'n kennisfunksie.9. p 163: 2, p 162-163: 8. p 60-63

- Die aanpassingsfunksie verwys na die verwantskap tussen individue en hul omgewings en die pogings van individue om genot of bevrediging te optimaliseer en pyn en straf te minimaliseer. Ten einde bogenoemde doel te kan bereik, word relatief gunstige houdings ingeneem teenoor produkte, handelsmerke of winkels wat aan die verbruiker plesier of opwinding verskaf en ongunstige houdings jeens daardie produkte of winkels wat hul mishaag.

- Ego-beskermende funksies verwys na die pogings wat individue aanwend om hul eie ego's te beskerm teen onaanneemlike prikkels, hetsy intern of ekstern. Navorsing het getoon dat baie meer nie-rokers as rokers artikels wat handel oor die gesondheidsgevare verbonde aan die rookgewoonte lees, terwyl die bemarkers van versekering, skoonheidsmiddels, medisyne en dieet-produkte van beroepe op vrees gebruik maak ten einde die verkope van hul produkte te bevorder. ${ }^{2,0} 162$

- Terwyl heelwat houdings daarop ingestel is om te voorkom dat die verbruikers hulle ware karakters openbaar, vervul ander houdings die funksie waardeur individue uiting kan gee aan hul geaardhede en sclfbeelde. Verbruikers vind so geleenthede om eie waardes te uiter deur middel van die produkte of handelsmerke wat hulle koop, asook die winkel of plek waarby dit gekoop word. In hierdie wyse vervul houdings ' $n$ waarde-uitbeeldende funksie.

- Die kennisfunksie dien as 'n middel waardeur die individue betekenis heg aan die ongeorganiseerde wêreld rondom hulle. Hierdie betekenisse is afkomstig vanuit die standaarde en verwysingsraamwerke wat houdings skep.

\section{Eienskappe van houdings}

- Gereedheid om te handel. Houdings voorsien die verbruiker van onmiddellike oplossings sonder dat die verbruiker deur ' $n$ bepaalde aanleer- of denkproses hoef te gaan. 'Consumer attitudes function somewhat like a program functions for a computer. A computer acts as it is programmed to act. Consumers, through their attitudes, also act according to how they are "programmed", 2. 164. 'n Verbruiker se houding vereenvoudig dus sy reaksieproses, verkort sy besluitnemingsproses en verminder die hoeveelheid inligting wat nodig is vir die besluitnemingsproses.

- Houdings beskik oor rigting, met ander woorde houdings kan òf positief òf negatief neig. Dit verklaar waarom die beeld wat ' $n$ verbruiker van 'n kleinhandelsonderneming vorm ò gunstig òf ongunstig kan wees. Die gewildheid van die semantiese differensiaal - waar pare direk teenoorgestelde byvoeglike naamwoorde of beskrywende frases op 'n sewe-punt skaal van mekaar geskei word - as die instrument vir meting van winkelbeeld word deur hierdie eienskap van houdings verklaar.

- Die intensiteit van houdings kan wissel. So kan 'n verbruiker 'n besonder sterk gunstige, 'n effens gun- stige, 'n neutrale of 'n besonder sterk ongunstige houding teenoor 'n bepaalde winkel openbaar. Gevolglik word skalingstegnieke soos die Thurstone, Likert en Guttman skale maar veral die semantiese differensiaal gebruik om winkelbeeld te meet. ${ }^{11}$

- Houdings volg 'n bepaalde struktuur - daar is met ander woorde 'n element van ooreenstemmigheid in 'n verbruiker se oortuigings, gevoelens en houdings. 'n Persoon wat byvoorbeeld 'n konserwatiewe houding jeens politiek inneem sal gewoonlik ook konserwatief in kleredrag, eetgewoontes, besteding, ensovoorts wees. Hierdie eienskap van houdings bring mee dat die winkelbeeld wat deur ' $n$ bepaalde afdeling of faset van ' $n$ kleinhandelaar se bemarkingstrategie, soos advertensie, vensteruitstalling, gehalte diens wat gelewer word, by 'n verbruiker vorm, 'oorgedra' kan word na ander afdelings of bemarkingstrategieë. Die gunstige beeld wat keurige vensteruitstallings skep kan meebring dat die verbruiker ook die interne uitleg van die winkel of die gehalte produkte wat aangehou word, gunstiger beoordeel.

- Die volledigheid van houdings kan wissel. Verbruikers se houdings is nie altyd gebaseer op volledige inligting nie, alhoewel hul dit self as volledig beskou in die sin dat hulle self die ontbrekende inligting invul. 'n Verbruiker kan 'n verkoopsman as onbevoeg of oneerlik beskou, geoordeel op slegs een enkele misstap wat die verkoopsman begaan het. Bovermelde eienskap verklaar ook die feit dat verbruikers meer in 'n advertensie 'lees' as die boodskap wat feitelik oorgedra word. 'Just as we instinctively make judgements about another person from his clothing and his mannerisms, so does the shopper believe she can abstract symbolic cues from advertising'. ${ }^{12}$ Die feit dat verbruikers self die ontbrekende inligting invul, verklaar die stelling van Martineau dat verbruikers deur middel van advertensies ' $n$ beeld van 'n winkel kan vorm al het hulle nog nooit self die winkel besoek nie. ${ }^{13}$

\section{Faktore wat houdingsvorming beïnvloed}

Alhoewel die faktore wat aanleiding gee tot die vorming van houdings dikwels verborge en indirek is, word dit hoofsaaklik gevorm deur persoonlike ondervinding, eksterne invloede en kulturele waardes. ${ }^{14}$ Die primêre mag in die vorming van verbruikers se houdings is dit wat intern tot die persoon is en dit wat hy uit vorige ondervindings geleer het. Dit stel hom in staat om vir hom 'n verwysingsraamwerk saam te stel wat sy houdings weerspieël.

Eksterne faktore wat die vorming van houdings beïnvloed, is dikwels toe te skryf aan beïnloeding deur vriende, ouers, opvoeders, bure, kerklike organisasies en politieke verbintenisse. Hierdie groepe het invloed op verbruikers se houdings omdat hul sekere waardes by die persoon skep, sowel as sekere inligting aan die individu oordra. As lede van so 'n verwysingsgroep dus 'n ongunstige houding, dus ook 'n ongunstige beeld, jeens 'n spesifieke winkel inneem, kan die houding oorgedra word op ander lede van die groep - al het hulle self nie eers persoonlike ondervinding van die winkel nie. 3. D 149

'n Verbruiker se bestaande of vorige kulturele omgewing beinvloed ook sy houdings. Dit geskied deurdat 
sekere gebruike, morele standaarde en tradisies die verbruiker se houding en dus optrede in vreemde of nuwe situasies sal beïnvloed.

\section{Kan houdings verander word?}

Die vraag ontstaan of ' $n$ bemarker of kleinhandelaar verbruikers se houdings jeens ' $n$ winkel in 'n gunstiger rigting kan verander. Die vraag kan deels beantwoord word deur daarop te wys dat alhoewel daar 'n mate van stabiliteit in verbruikershoudings bestaan, dit nie heeltemal staties is nie en dus wel kan verander. Die sterkte van die verbruiker se houding sal 'n rol speel - sterker houdings is baie moeiliker veranderbaar as swakker of meer neutrale houdings.

Een faktor wat 'n groot rol speel in die vorming van houdings, naamlik inligting, kan ook effektief aangewend word om verandering teweeg te bring. Die uitgangspunt moet wees dat iets nuuts aan die verbruiker gekommunikeer moet word wat die ou idees, opvattings of beeld moet hervorm. 'It should be different and creative. The information must be strong enough or novel enough to shift the attitude. Old ideas, even if they fit the overall attitude set, will not change an existing attitude."'

Volgens Stanton" o." sal verbruikers se houdings slegs suksesvol deur kommunikasie verander word mits aan een of meer van die volgende voorwaardes voldoen word:

Indien treffende inligting omtrent die produk of winkel voorsien word wat die verbruiker se kognitiewe evaluasies van die produk of winkel sal verander.

- Indien 'n sterk emosionele aanslag gemaak word wat die verbruiker se emosionele evaluasie van die produk of winkel sal verander.

- Indien die verbruiker beweeg kan word tot aksie of optrede wat bestaande voorkeure en houdings sal weerlê.

Hierdie voorwaardes beklemtoon die feit dat verbruikers se beeld van ' $n$ bepaalde winkel nie slegs deur fisiese veranderings aan die winkel verander kan word nie, maar dat dit ook op 'n subjektiewe wyse kan geskied.

Die beeld van 'n kleinhandelsonderneming sal dus direk afhang van die verbruikers se houdings jeens die winkel in die algemeen of jeens sekere beleidsinstrumente. Die kleinhandelaar moet die verbruikers se houdings jeens die winkel navors en sy kleinhandelresep ('retailing mix') so saamstel dat gunstige houdings versterk word en ongunstige houdings onderdruk of verander word. By die bepaling van verbruikers se houdings moet kleinhandelaars daarteen waak dat hul nie net vasstel wat verbruikers se houdings is nie, maar hulle moet ook bepaal watter houdings verbruikersgedrag werklik beïnvloed. 'Attitudes toward features which are most closely related to preference or to actual purchase decisions are said to be determinant, the remaining features or attitudes - no matter how favourable - are not determinant. Marketers obviously need to know which attitudes or features lead to - or "determine" - buying behavior, for these are the features around which marketing strategy must be built." ${ }^{16}$ Sommige eienskappe van ' $n$ winkel hou verband met verbruikers se houdings, en dus ook beeld, jeens die winkel in dié sin dat indien die eienskappe nie aanwesig is nie, dit hul houdings nadelig sal beïnvloed, maar indien dit aanwesig is, dit nie as werklike rede dien waarom ver- bruikers die betrokke winkel ondersteun nie. Ter illustrasie: indien verbruikers byvoorbeeld versoek word om die kenmerke van winkels in volgorde van belangrikheid te plaas, word gehalte van voorraad wat aangehou word dikwels as eerste keuse vermeld. Dit kan egter gebeur dat dieselfde verbruikers nie die verskillende winkels as verskillend ten opsigte van die gehalte van voorraad wat aangehou word, beskou nie. Gevolglik is die verbruikers se houding aangaande die gehalte van voorraad wat aangehou word nie ' $n$ bepalende (werklike) houding by die uitoefening van 'n keuse tussen winkels nie. Die kleinhandelaar moet dus daardie werklike houdings navors wat verbruikers se winkelbeeld bepaal of beïnvloed en dan daarby probeer aanpas.

\section{Samevatting}

Die beeld wat verbruikers van 'n bepaalde kleinhandelsinstelling vorm, word deur bepaalde funksionele insette soos voorraad, verskeidenheid en gehalte; prysbeleid, advertensies, verkoopspersoneel, en eksterne- en interne uitleg van die winkel beïnvloed. In die beeldvormingsproses is daar egter ook subjektiewe kragte werksaam wat grootliks te wyte is aan die verbruikers se individuele evaluasie van bogenoemde funksionele aspekte. Die werking van hierdie subjektiewe kragte kan beter begryp word indien gelet word op die faktore wat verbruikersgedrag beinvloed.

In hierdie artikel is twee faktore wat verbruikersgedrag beïnvloed, naamlik persepsie en houdings, ontleed in ' $n$ poging om te illustreer hoe hierdie subjektiewe kragte die verbruiker se beeldvormingsproses beïnvloed. Op 'n soortgelyke wyse kan die bestudering van ander faktore wat verbruikersgedrag beïnvloed soos die aanleerproses, persoonlikheid, kultuur, sosiale groepe, die gesin, daartoe bydra dat meer lig gewerp word op die komplekse proses van beeldvorming. Sodoende kan die kleinhandelaar 'n beter begrip vorm van hoe die verbruikers die bemarkingstrategieë wat benut word, 'verwerk' tot 'n winkelbeeld wat die verbruiker se reaksie - naamlik om die kleinhandelaar te ondersteun al dan nie - sal bepaal. Hy kan dan sy strategie en reklame deur hierdie kennis veel meer doelgerig en doeltreffend maak.

\section{Summary}

Perception and attitude are two subjective forces influencing the consumer's image of a specific retail store.

Consumer behaviour is influenced by the fact that perception is subjective since the image of a store is not only dependent on the functional factors contained therein, but also by the way these factors are conceptualized. The consumers conception is selective since not all stimuli can be internalized and only a few are reacted to. Perception is not permanent and thus images can be changed. Technical factors, the human mind, previous experiences, moods and cultural and social factors influence individual perception.

Consumer attitudes contain both positive and negative evaluations and these have four functions; viz. to adapt, protect the ego, reflect values and to give meaning. Attitudes have certain essentials which are: the ability to act speedily through the reduction of the decision-making process; they are directional, either negative or positive; they vary in intensity and there is an element of continuity regarding the consumer's beliefs and feelings. 
Attitudes are not always formed through comprehensive knowledge - symbolic cues are abstracted from partial information and advertising. Attitude formation is influenced by factors which are often indirect, such as personal experience, external influences and cultural values which contribute to an individual frame of reference. Change can be brought about through communication; if cognitive valuation is changed; a strong emotional appeal made or the consumer be convinced of an action to negate existing preferences.

Extensive study of other factors influencing consumers behaviour, such as the learning process, personality, social groups, the family, etc., may all contribute to a better understanding of how the consumer implements marketing strategies to form an image of the retail store - this knowledge may benefit the retailer to direct and utilize his strategies and public relations to better advantage.

\section{Verwysings}

1. Jooste, C.J. Die beeld van die kleinhandelsonderneming as beïnvloeder van winkelondersteuning, Bedryfsleiding, 9: 1, 1978 p. 20.

2. Walters, C.J. Consumer behavior - Theory and practice, Richard, D. Irwin, Homewood 1974.

3. Myers, J.H. \& Reynolds, W.H. Consumer behavior and marketing management, Houghton Mifflin Company, Boston, 1967, p. 3.
4. Marquardt, R.A., Makens, J.C. \& Roe, R.G. Retail management: satisfaction of consumer needs, The Dryden Press, Hinsdale, 1975 , p. 59.

5. Enis, B.M. An analytical approach to the concept of image, Calif. Mgmt. Rev. Somer 1967, p. 51.

6. Larson, C.M., Weigand, R.E. \& Wright, J.S. Basic retailing, Prentice-Hall, Englewood Cliffs, 1976, p. 121.

7. Rickert, G.H., Myer, W.G. et al. Retailing: Principles and practice, McGraw-Hill Book Company, New York, 1974, p. 316.

8. Robertson, T.S. Consumer behavior, Scott, Foresman and Company, Glenview, 1970, pp. 46-65, gee 'n opsomming van die verskillende skole se standpunte.

9. Katz, D. The functional approach to the study of attitudes, Pub. Op. Quar., Somer 1960, pp. 163 - 204.

10. Stanton, W.J. Fundamentals of marketing, McGraw-Hill, New York, 1975, p. 86.

11. Vir ' $n$ volledige bespreking van die meting van winkelbeeld sien Jooste, C.J. 'n Winkelbeeldstudie van kleinhandelsinstellings met spesifieke verwysing na afdelingswinkels, ongepub. proefskrif, Universiteit van die Oranje-Vrystaat, Januarie 1977, pp. 97- 107.

12. Martineau, P. Personality of the retail store, Horv. Bus. Rev., Jan. - Feb. 1958, p. 52.

13. Martineau, P. Motivation in advertising, McGraw-Hill Book Co., New York, 1957, pp. 174-175.

14. Markin, R.J. The Psychology of consumer behavior, Prentice Hall, Englewood Cliffs, 1969, pp. 200-201.

15. Bell, M.L. Marketing: Concepts and strategy, Houghton Mifflin Company, Boston, 1972, p. 241.

16. Myers, J.H. \& Alpert, M.T. Determining buying attitudes: meaning and measurement, J. Mark., Okt. 1968, p. 13. 